\title{
Ocupar ou construir espaços? Uma Ética Cívica do Social
}

\author{
Take up or build spaces? A civic ethics of Social
}

\author{
Eni de Lourdes Puccinelli Orlandi ${ }^{1}$ \\ Universidade de Campinas
}

\begin{abstract}
Violência, evidência, natureza: "Ele não saía dessa ideia sombria de que a verdadeira violência é a do "isto vai por si'; o que é evidente é violento, mesmo se esta evidência é representada docemente, liberalmente, democraticamente; o que é paradoxal, o que não faz sentido, o é menos, mesmo se é imposto arbitrariamente: um tirano que promulgasse leis absurdas seria a ser tomado como menos violento que uma massa que se contentaria de enunciar "o que vai por si": o" natural" é, em suma, o último dos insultos"(Barthes, R. 1975)
\end{abstract}

\section{Introdução}

Partindo da crítica posta pela relação entre cidadania - com dominância da instância do jurídico - e civilidade (H. Arendt, Sennett e outros) - com dominância da instância da pluralidade regida pelas formas de administração (eu diria "governo") - e tomando a cidade como projeção de uma topografia discursiva (relações espaciais) onde jogam a unidade e a dispersão, procuraremos compreender como se dão as relações entre o pessoal e o impessoal, a exterioridade e a interioridade, a vizinhança e o banimento, que vão dar sentido aos mecanismos de sobrevivência da cidade e de seus habitantes.

Como significam as formas de vida, as manifestações e as posições-sujeito nisso que estamos chamando de tópica cívica, se tomamos em conta o espaço da cidade? Como o consenso produzido pelas políticas urbanas e sustentado pela prática da "opinião" aí significa?

A tópica cívica pode ser compreendida, a partir da articulação entre relações espaciais e formações sociais, como lugares institucionais que dão forma e sentido aos sujeitos urbanos, aos "cidadãos", e ao modo como eles significam e se significam nos movimentos sociais, em suas manifestações: o manifestante/o vândalo; o habitante/ o morador de rua; etc.

A partir de pressupostos teóricos da análise de discurso, sobre a constituição dos sujeitos em seus processos de identificação, e da própria forma da sociedade, tendo a cidade como espaço fundamental em que isso se dá, procuraremos compreender o que é civilidade, e os sentidos do cidadão e da própria cidade, no confronto do simbólico com o político. Tomamos como lugar específico de produção o espaço urbano como observatório desse confronto.

\section{Instituição, Poder e Espaço Imaginário: a tópica cívica}

Partimos assim da projeção de lugares institucionais como lugares discursivos ${ }^{2}$ (de produção de sentidos e de processos de identificação de sujeitos) para pensarmos o que chamamos de tópica cívica: não há cidadania em abstrato, sobretudo se pensamos as atuais formas de relação do Estado com os seus sujeitos histórico-sociais. O que há são sítios,

\footnotetext{
${ }^{1}$ Doutora em Linguística. Professora colaboradora do IEL/UNICAMP. E-mail: enip@uol.com.br

${ }^{2}$ Não estamos aqui falando dos lugares sociais e sua projeção, através de formações imaginárias, no discurso, constituindo as posições sujeitos. Estamos falando de lugares institucionais, o que implica a administração e o governo. A projeção desses lugares institucionais atribui ao sujeito posições da chamada cidadania. Materializa-as.
} 
lugares de definição, em que se configuram processos de manifestação concreta de sentidos de cidadania. Estes sítios de significação, por sua vez, se articulam, muitas vezes, com o que tenho chamado de "locus significandi" (locus de significância), que são espaços materiais concretos que determinam, pela conjuntura em que se configuram, a produção de sentidos. São esses lugares, esses sítios que nos interessam.

Nossa hipótese, já posta anteriormente, é de que há duas formas ideológicas que regem o imaginário citadino, nas suas atuais condições: 1. O mito da completude criando a interpretação do fragmentário, da desagregação; 2 . em uma perspectiva neo-liberal, o fato de que a reciprocidade, a solidariedade cedem lugar à rivalidade, à competição, à marginalidade.

Da relação dessas duas formas ideológicas resulta uma declinação particular da noção de cidadania (direito) e de civilidade (pluralidade) - relação entre o jurídico e o administrativo - que produz uma divisão, que coloca à margem, segrega. Quanto ao político, ele se significa predominantemente pelo administrativo ou pelo que chamaria de política (partidária).

Nessas condições, e de acordo com as conjunturas, o jogo pessoal/impessoal, exterioridade/interioridade, vizinhança/banimento estabelecem sentidos para o que podemos agrupar sob a categoria de marginalidade, "delinquência" (ligada a práticas individuais), que é objeto de nossas elaborações.

Apoiando-nos em uma visão tópica da cidade, com seus sítios de significação, objetivamos compreender a confluência de dois movimentos - o da expansão e o da inserção em que a delinquência pode ser percebida como sintoma do acréscimo, do a-mais necessário para a sobrevivência, ao mesmo tempo em que aponta para o "resto". O jogo entre o administrativo e o jurídico rege o a-mais, significando-o em suas condições de existência ${ }^{3}$.

Temos assim uma "hybris"4 cívica que vai significar a relação entre o público e o privado, a interioridade e a exterioridade, a pessoalidade e a impessoalidade, a segregação, a singularidade e a pluralidade. O já-significado, o muito cheio, o espaço saturado da urbanidade, e da cidadania.

Deslocando os sentidos de cidadania e de civilidade, retomamos a metáfora de Joyce, do homem caminhando pela cidade, com suas incertezas existenciais, deslizando para a do homem não imerso na incerteza, mas fazendo face a sua impossibilidade ${ }^{5}$ (dele como homem, da cidade como sítio de sobrevivência): espaço saturado, sítios suturados, o excrescente (a escalada da insignificância), o ignorado ("não tem ninguém").

Na cidade, ele é o que está sempre no "a-mais". Não falamos do espaço mensurável, nem do espaço fragmentado. Há outra ordem que se faz porque não há mais espaço a ocupar: é a instância do espaço saturado. O homem citadino está além de. Não são processos, trajetos; são inserções ou expansões. Rupturas. Extradição.

Daí a importância da noção de acréscimo. Vemos a cidade como um aglomerado de "amais". Quantidade que, em princípio, excede, a cidade se estrutura no excedente. Que sentidos, então, respondem a esse a-mais? Que sujeitos aí se constituem?

\footnotetext{
${ }^{3}$ Para o analista de discurso, ao contrário de outras teorias da linguagem, o mundo existe, ou seja, há o real da língua e há o real da história, portanto o espaço social não é só uma miragem produzida pela linguagem. Ele é espaço material concreto com suas práticas regidas pelo poder e pelo imaginário social.

${ }^{4}$ A hybris é um conceito grego que significa desmedida, no sentido de cometer excessos, ultrapassar, exceder, transgredir. Cristianizado latinamente torna-se "Pecar". "Errar".

5 Aqui se reapresenta o "homem impedido" produzido pela nossa história, a do capitalismo, em nossas formações sociais (Cf. Tchekov).
} 
Como ligamos a noção de consenso à de opinião e ao "lugar comum", visto como lugar social público, de experiência comum - cum+sensus - é nessa direção que vai nossa reflexão: a que pensa o consenso face à excrecência, à saturação, à delinquência. Sem esquecer que o consenso se constitui por processos de apagamento, de silenciamento e representa o ponto de giro da segregação.

Já adiantamos que, quando falamos em "opinião" aí faz efeito a ideologia e a presença social da mídia, ou das mídias digitais. Importa realçar que as mídias digitais mudaram a gestualidade, a relação dos sujeitos com suas imagens. A imagem e o que é dito não precisam coincidir. Há o que eu chamaria de um espalhamento da identidade deste sujeito. Fragmentamse e esfarelam-se. Isto porque mudou a relação dos sujeitos com a linguagem. Mídias, a própria generalização da análise de discurso, tomada como senso comum, fizeram com que o sujeito tenha, ou se "perceba" em, uma relação que eu chamaria de visceral com a linguagem. Este sujeito debruça-se sobre si em continuidade. O movimento das minorias está aí para comprovar isto: judicialização e militância do "eu" em permanência.

\section{Distinções e determinações do espaço}

A partir do que referimos acima como sendo a tópica cívica, podemos pensar o espaço com diferentes atribuições. Sabemos que o espaço, pensando-se a cidade, é um espaço de significação, suscitando interpretação. Além disso, como já tivemos a ocasião de afirmar em outros trabalhos, o espaço, quando se trata da cidade, sofre diferentes determinações, de tal forma que, na atualidade, a relação entre o político e o simbólico se faz na forma da sobredeterminação do espaço social pelo espaço urbano, ou seja, há uma prevalência do espaço urbano na significação do espaço social. As relações sociais se significam pelo urbano e suas especificidades.

Além dessa (in)distinção, temos também feito uma diferença, entre ordem e organização, que se reflete sobre a diferença que fazemos quando se trata de pensar a cidade (em sua ordem) ou em sua organização (urbana). A organização urbana está presente de forma precípua nos discursos administrativos, dos especialistas e também dos sujeitos comuns, os usuários do espaço urbano. Sujeitos generalizados (R. Barthes, 1975) ${ }^{6}$. Assim, podemos dizer que, ao pensar a cidade, temos de atentar a estas distinções. Em minhas reflexões tenho privilegiado a compreensão da ordem da cidade, e suas declinações quanto à organização urbana, na forma como esta ordem está significada no social, ou o significa. Isto para procurar encontrar o real da cidade. E compreender a relação cidade e sujeitos que aí se inscreve.

\section{Linguagem, sujeito, sociedade}

Para pensarmos a tópica cívica não podemos ignorar a relação entre espaços, entre sujeitos e entre sujeitos e sociedade. E o sujeito de que tratamos é o sujeito discursivo, ou seja, o indivíduo interpelado em sujeito pela ideologia. Sujeito de linguagem, sujeito social e histórico, constituído na articulação simbólico-política.

\footnotetext{
${ }^{6}$ Diz Barthes, após apresentar fotos suas, de sua infância e juventude, e passar a escrever sobre ele mesmo, entrando, assim, no que ele chama de" imaginário da escrita": "Desde que produzo, desde que escrevo, é o próprio Texto que me despossui (felizmente) de minha duração narrativa. O Texto não pode contar nada; ele leva meu corpo para outro lugar, longe de minha pessoa imaginária, para uma espécie de língua sem memória, que já é a do Povo, da massa insubjetiva (ou do sujeito generalizado), mesmo se eu ainda estou separado dele pela minha forma de escrever."
} 
As teorias sociais que falam do sujeito, em geral, pensam um sujeito centrado, onipotente, mestre de si e de suas vontades, na relação com a sociedade. Esta também já estruturada. O que, em discurso, chamamos, no caso do sujeito, de subjetivismo idealista, ou individualismo subjetivista. E, no do sentido, de objetivismo abstrato. A sociedade "lá".

Vamos tomar, para ilustrar o que estamos dizendo, uma teoria de movimentos sociais como a de A. Touraine. Ele propõe que se pensem os movimentos sociais a partir de um conflito central. Distingue, então, o conflito que leva o sujeito em luta contra o mercado e as técnicas, de um lado, e, de outro, o que luta contra os poderes autoritários. Chama a isto de conflito cultural, atual, que se distingue tanto do que havia antes (o da sociedade industrial) que se apoiava no econômico, ou o do início da modernidade, que era um conflito político. Os atuais se organizam em redor do controle dos modelos culturais. E o que chama de "cultura", afinal?

Ele afirma que um conflito social, com um projeto cultural, é sempre definido por referência de um sujeito. Portanto o cultural tem a ver com a referência de um sujeito. E mais: aborda questões de liberdade, de projeto de vida, de respeito a direitos fundamentais que não são apenas ganhos materiais e políticos. Seriam "culturais"? Penso que sim, e relativos ao sujeito. Deixa-se de falar em movimento social para se falar em movimento societal, pois este associa o projeto cultural a um conflito social. Já a partir de 1960, segundo Touraine, em sua crítica a ideia de povo como disfarce do Estado, os movimentos não devem mais se chamar societais, mas culturais, visto que as ações coletivas dos movimentos culturais tendem a defender ou a transformar uma figura em sujeito: os das mulheres, o da ecologia política e a defesa das minorias. Tornam-se contraditórios desde que entrem em questão os conflitos de classes. Veja-se o caso das cotas.

Como resultado, há uma priorização do sujeito como centro da análise, e a identidade social, que antes era definida pela relação com o sistema social, agora passa a se pautar pelo próprio sujeito, diz Touraine (grifo nosso). E têm-se mais movimentos de afirmação do que de contestação. O que é este "próprio sujeito"? A afirmação desdenha a contestação? Que lugar tem, nesta reflexão, a resistência, o político, a ideologia? Que sujeito é este?

Discursivamente, o que temos são diferentes formas de assujeitamento, diz Pêcheux, pensando-se a historicidade, as diferentes conjunturas. Esta é uma questão ideológica que acarreta a necessidade de diferentes tipos de resposta dos sujeitos. O que quero dizer é que nem o sujeito é constituído do mesmo modo - embora se constitua sempre pela interpelação do indivíduo em sujeito - nas diferentes conjunturas, nem a resistência, ou a contestação é a mesma nas diferentes épocas.

Penso que uma das dificuldades de se pensar esta questão do assujeitamento, logo, a do sujeito, nas teorias sociológicas, é que no caso presente, que tomei como referência, os sentidos do cultural se substituem ao social e se indistinguem. Na medida em que se procura, discursivamente, distinguir social e cultural, há uma separação. E aí podemos ver os efeitos ideológicos da tomada de um pelo outro, presentes, por exemplo, no que falamos do subjetivismo idealista, a de um sujeito agente, dono de sua vontade, responsável etc. O efeito sujeito centrado, que a análise de discurso critica. No domínio da posição subjetivista, há também a dominância da dissociação: Indivíduo e Sujeito; Linguagem e Sociedade. Estas disjunções resultam da incompreensão da ideologia e da interpelação do indivíduo em sujeito. Sujeito que é, na sua constituição mesma, sujeito social. Posição-sujeito em que o político e o social se articulam simbolicamente. Se fizermos entrar em conta a ideologia. 
Na posição sociológica de Touraine, a ideologia entra em oposição às práticas, já para a análise de discurso ela, a ideologia, é uma prática. Finalmente, também nos é estranho pensar o sujeito, na busca da liberdade, arriscando cair no homogêneo, pela obsessão da identidade.

Também neste ponto, só se pode afirmar isto se pensamos um sujeito mestre de si, onipotente, em oposição à sociedade. E não um sujeito efeito de interpelação pela língua e pela sociedade, determinado historicamente.

\section{Ocupar ou Construir o espaço social?}

Após estas considerações sobre a sociedade, o sujeito e a ideologia, e remetendo à nossa reflexão sobre a tópica cívica em que a questão dos lugares vincula-se às instituições e à constituição da cidadania e à civilidade, podemos afinal distinguir o que estamos pensando como ocupação ou construção.

A noção de ocupação, neste caso, está vinculada à ideia de homogeneidade, saturação, e a de uma sociedade já pronta e inerte, já lá. Mas, na perspectiva que nos propomos, a sociedade está em contínuo movimento e na constituição de diferentes posições-sujeito, constitui-se permanentemente - reproduzindo ou transformando - a formação social. Esta é uma questão que apela às formas de individuação dos sujeitos pela articulação simbólicopolítica gerida pelo Estado, com suas instituições e discursos; condição prévia da identificação dos sujeitos com as formações discursivas de que resultam as distintas posições-sujeitos e a diversidade de sentidos.

Para nós, ocupar pode ser construir, quando pensamos o espaço social, e construir, neste caso, é produzir um sentido com sua forma histórica, de reivindicação de independência e de constituição de uma posição sujeito que se respeita e cuida do social que constrói. Nesta distinção, podemos dizer que ocupar ou construir o espaço são duas formas de relação social e de constituição de "lugares de poder", de "posição autorizada", de "legitimidade" na formação social.

Com Pêcheux, aprendi a olhar x para compreender y e também a expor o olhar à opacidade. Daí que falar da ocupação do lugar social, ou da construção do lugar social que se reivindica, é também falar da mídia, das redes, do político. Pensando o funcionamento disso tudo (redes, mídia, conflagrações políticas, mundialização etc) podemos afirmar que há uma mudança da presença do discurso social, mudança da estrutura e do acontecimento do discurso social. O que acarreta também uma transformação nos modos de ocupação, ou melhor, de construção dos lugares sociais, pela sua ocupação. O que afeta a relação do sujeito com os "outros"; a alteridade. Sem esquecer que, pensando nossa forma-sujeito histórica, a do capitalismo, há divisão dos sujeitos entre si, mas também do sujeito consigo mesmo.

Para além da divisão, o que aprendemos com a análise de discurso, a partir da noção de posição-sujeito, é que somos múltiplos. Segundo Nietzsche, a moral existe para calar a pluralidade em mim e fazer emergir o sujeito forjado na identidade coletiva do "troupeau", da manada (2012). De nossa parte, temos desenvolvido reflexões sobre a não exatidão, a não coincidência dos sujeitos seja com os sentidos, seja com os outros sujeitos e mesmo consigo próprio. Assim, quando falamos em "ocupar" no sentido de construir espaços sociais, estamos pensando neste sujeito múltiplo, plural e nas possibilidades que a construção de espaços abre para a relação dos sujeitos entre si e do sujeito com ele mesmo. Processo, assim, sempre inacabado e aberto a novas "ocupações", que não só a de se legitimar, ou de produzir 
poder. Mas de posições-sujeito outras e não redutíveis à coerção da "manada". O que significa, afinal, não apenas reproduzir a sociedade, mas, no movimento da sociedade, produzir outros espaços sociais.

Realizando assim o passo que vai da moral à ética, e que, aqui, chamo de ética cívica, a que abre espaço para outros processos de significação, que tomam distância em relação à cristalização de sujeitos no padrão fixado social: "torne-se o que você é", diz Nietzsche. Ou seja, toma-se distância, pois, ser livre é tomar o caminho da existência por decentramentos sucessivos face a si mesmo, ao que nos determina para o idêntico. Repetição. Aí reencontro o que tenho trabalhado como sentidos em fuga (polissemia e dispersão, espalhamento), e a não coincidência do sujeito consigo mesmo. Ao construir um espaço social abre-se a possibilidade de tornar-se o que se é, e não apenas ocupar o lugar do que já é. Do já-lá.

Construir (se) um espaço social é dinamizar as possibilidades da formação social/sociedade em seu real histórico, é movimentar (se). E aqui lembro a distinção que proponho entre movimento social (organização, imaginário social) e movimento da sociedade (ordem, real da história). O que, para finalizarmos retoma o que eu disse no início desta reflexão distinguindo a política do político, sendo este que, na sua articulação ao simbólico, nos remete à incompletude, ao equívoco, à possibilidade de rupturas, de resistência talvez. Minha forma de pensar esta questão traz para o foco o princípio da alteridade e o da liberdade. Da resistência enquanto possibilidade não só de se opor ${ }^{7}$, mas ser "outro". E, eu diria, distanciar-se (e aqui refiro novamente a Niezstche $)^{8}$. E manter à distância não é estar fora (assim como é impossível estar fora da história). Retomando Pêcheux, eu diria, é olhar o dedo e não a lua. Em outras palavras, não ser usuário (redução pragmática), mas ser sujeito, individuar-se em uma posição-sujeito que resiste ao que se impõe pela ideologia, o que satura e não deixa lugar à incompletude, à historicidade, ao equívoco. Se a ideologia não é um ritual sem falhas, como afirma Pêcheux, é possível não sucumbir ao comum (gemein: senso comum, consenso), como diz Nietzsche. Não alienar-se. Historicizar (se), enquanto ser histórico e simbólico, interpelado pela ideologia e constituído pelo político. Por-se em outro "lugar". O do irrealizado.

\section{REFERÊNCIAS}

RENDT, H. A Condição Humana. 10. ed. Rio de Janeiro: Forense Universitária, 2007. BARTHES, R. Roland Barthes, par lui même. Paris: Eds du Seuil, 1975.

\footnotetext{
${ }^{7}$ Lembro aqui S. Lagazzi que sempre insistiu em mostrar que resistir não se reduz à oposição.

${ }^{8}$ Em sua Filosofia da Interpretação, Nietzsche dá amplo lugar ao incompreensível, à margem de manobra, às sutilezas da interpretação, ’a individualização. Falando da "vontade de sistema" diz Nietzsche que ela se expressa por uma doutrina doutrina que se arroga a compreensão supraindividual/universal, o que, segundo Nietzsche, é um preconceito moral, uma patologia, sintoma de "cansaço da vida" - que é a exigência incondicional por uma compreensão inequívoca e de validade universal. Isto, para Viesenteiner (2013) é a instrumentalização de um imenso processo de desindividualização de argumentos, a criação de um sistema de conceitos e uma lógica que seja capaz de proceder às suas derivações, cujo fundamento é "o pendor predominante de considerar o semelhante como igual", bem como "a negação da fluidez da vida", a exigência do "gemein", o algo em comum, da compreensão universal, que recusa Nietzsche, e o apagamento, diria eu, das condições peculiares de vida, condições de existência. Essa "vontade" é uma metafísica, que vai em direção a um grande processo de vulgarização. Segundo Nietzsche, esta posição não toma em conta a superação da compreensibilidade, da metacompreensão, o distanciamento da situação na própria situação. E esta é sua proposta em sua filosofia da interpretação, que é uma filosofia da individualidade, que desestabiliza conceitos e amplia as margens de manobra da interpretação. O que significa aí "ampliar"? Como ele diz, queremos ser compreendidos e não ser compreendidos. Afirmação que nos remete, de certo modo, à de $M$. Pêcheux, "a linguagem serve para comunicar e para não comunicar”(1975).
} 
NIETZSCHE, F. A Gaia Ciência. São Paulo: Cia das Letras, 2012.

ORLANDI, E. "Políticas Institucionais: a interpretação da delinquência", Bolema,v.23, n.36, p. 625-638, 2008.

PÊCHEUX, M. Les Vérités de La Palice. Paris: Maspero, 1975.

SENNETT, R. O Declínio do Homem Público: as tiranias da intimidade. São Paulo: Companhia das Letras, 1988.

VIESENTEINER, J. L. "Nietzsche e o projeto crítico de superação da compreensibilidade", Cadernos Nietzche, n. 32, 2013, p. 1-22. Disponível em: http://gen.fflch.usp.br/sites/gen.fflch.usp.br/files/u41/CN32 artigo12.pdf. Acesso em: 18 de set. 2019.

Recebido em: fevereiro de 2019.

Aprovado em: maio de 2019.

Como citar este trabalho:

ORLANDI, E. de L. P. Ocupar ou construir espaços? Uma Ética Cívica do Social. Traços de linguagem. V.3, n.1. , p.9-15, 2019. 